\title{
ACESSIBILIDADE E INCLUSÃO BÁSICA: UMA ABORDAGEM INTERDISCIPLINAR EM ESCOLAS DA REDE PÚBLICA MUNICIPAL DE JOÃO PESSOA-PB
}

\author{
BONIFACIO, lury Percyo Lemos (1); \\ SARMENTO, Bruna Ramalho (2) \\ (1) UFPB, Graduando em Arquitetura e Urbanismo \\ e-mail: iurybonifacio.ib@gmail.com \\ (2) UFPB, Doutora em Arquitetura e Urbanismo \\ e-mail: brunarsarmento@hotmail.com
}

\begin{abstract}
RESUMO
Este artigo objetiva estimular a conscientização e o interesse sobre inclusão e acessibilidade em comunidades escolares de ensino fundamental a partir do relato do projeto de extensão "Acessibilidade e inclusão básica: Uma abordagem multidisciplinar em escolas da rede pública municipal de João Pessoa-PB", desenvolvido no ano de 2017 na rede pública municipal de ensino desta cidade, por meio da apresentação dos conceitos fundamentais e práticas de acessibilidade e inclusão social, utilizando um processo colaborativo e interdisciplinar ${ }^{1}$ (entre Arquitetura e Urbanismo, Design e Terapia Ocupacional), com o desenvolvimento de meios para o compartilhamento e manutenção do tema no ambiente escolar.
\end{abstract}

Palavras chave: comunidade; universidade; troca de saberes; acessibilidade; inclusão.

\begin{abstract}
This article aims to stimulate awareness and interest about inclusion and accessibility in elementary school communities based on the report of the extension project "Accessibility and basic inclusion: a multidisciplinary approach in schools of the municipal public network of João PessoaPB", developed in the year of 2017 in the municipal public education network of this city, through the presentation of fundamental concepts and practices of accessibility and social inclusion, using a collaborative and interdisciplinary process (between Architecture and Urbanism, Design and Occupational Therapy), with the development of means of sharing and maintaining the theme in the school environment.
\end{abstract}

Keywords: community; university; exchange of knowledge; accessibility; inclusion

\section{INTRODUÇÃO}

O tema Acessibilidade vem sendo evidenciado desde a promulgação da NBR 9050 (ABNT, 2015), que trata da acessibilidade a edificações, mobiliário, espaços e equipamentos urbanos; e do Decreto Federal n 5.296 (BRASIL, 2004) que regulamenta as leis federais

\footnotetext{
1 Pesquisa realizada com o apoio da PRAC/UFPB, da qual participaram: Dra. Bruna Ramalho Sarmento (designer de interiores/mestre e doutora em arquitetura e urbanismo); Msc. Leandro Lopes (designer); Msc. Dhyego Nogueira (terapeuta ocupacional e mestre em arquitetura e urbanismo), além dos extensionistas (bolsista e voluntários): lury Bonifácio e Carolina Medeiros, alunos do curso de Arquitetura e Urbanismo/UFPB e Rafaela Behar, do curso de Terapia Ocupacional/UFPB.
} 


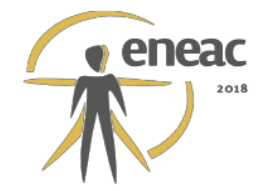

10.048 (BRASIL, 2000a) e 10.098 (BRASIL, 2000b) estabelecendo prazos e procedimentos para as ações voltadas à acessibilidade. Com isso, todas as edificações a serem construídas ou já em funcionamento precisam ser acessíveis, de forma a permitir o livre trânsito das pessoas com ou sem deficiências.

Segundo Duarte e Cohen (2004), o ambiente é como um ator que se relaciona com o usuário de forma a excluí-lo ou a incluí-lo. Muitas pessoas com deficiência não sentem falta apenas de um espaço acessível, mas também de um lugar em que desenvolvam suas habilidades. Quando essa interação não ocorre considera-se o ambiente como cerne e catalisador do processo de "deficiência".

Diante disso, as instituições públicas de ensino superior têm um papel importante enquanto disseminador da conscientização a respeito da acessibilidade, e de como esta é configurada na proposta da inclusão social. Um fator agravante para essa conscientização é gerado pela ausência, ainda fomentada, em se discutir a temática por grande parte da população, principalmente no tangente às pessoas com deficiências. Essas discussões são fragilizadas, sobretudo, nas redes de ensino (básico, médio ou superior), e são agravadas pela falta de adaptação dos espaços à diversidade de usuários, seja por questões referentes à idade, peso, altura, deficiências, situações de incapacidade ou mobilidade reduzida temporária (gestantes, lesionados, usuários de carrinhos de bebê, etc.) ou permanente (idosos). Os espaços educacionais deveriam traduzir os anseios e necessidades desses usuários, assim como, incentivá-los à realização das atividades, passando o ambiente construído a ter uma grande importância, também motivacional, mas constituem-se na realidade em barreiras físico-espacial e social.

O primeiro passo, e de importância fundamental, é que os usuários desses espaços tenham consciência em relação à influência da inacessibilidade na adaptação de suas instalações físicas ou de fatores atitudinais que impeçam ou dificultem o acesso, uso, permanência ou segurança de qualquer pessoa que desse espaço necessite. Esse posicionamento se dá tanto através de um projeto arquitetônico que atenda os princípios do desenho universal, como de ações que tragam a tona discussões sobre acessibilidade e participação social.

Quanto ao entendimento de barreiras, Bins Ely (2004) salienta que estas são muitas vezes destacadas a partir de propriedades físicas ou que restrinjam as capacidades físicas das pessoas, como aquele típico projeto que cria rampas para o cadeirante, e propõe que, a partir disto, está exercendo "acessibilidade". Para a autora, certamente o planejamento de espaços acessíveis são muito mais que rampas, tal como há muitas outras barreiras físicas além da escada e de um piso desnivelado. Nesse contexto, se discute barreiras em sua forma singular: o bebedouro que é muito alto para criança; a maçaneta em formato de bola, que é escorregadia e difícil de abrir; o piso que apresenta reentrâncias e dificulta a mobilidade de mulheres de salto alto ou que utilizam carrinhos de bebês; ou em outras instâncias, o aluno que não utiliza determinado equipamento por não enxergar a letra em tamanho e contraste suficiente; ou crianças mais novas que não tem áreas de recreação com brinquedos acessíveis à sua faixa etária. Esses exemplos denotam a incoerência que muitos planejadores e projetistas acolhem quando propõem ambientes "acessíveis" pensando unicamente em pessoas com algum tipo de deficiência ou ambientes que possuam "áreas acessíveis", enquanto o restante do projeto oferece dificultadores de todas as formas.

Segundo a Constituição Federal (BRASIL, 1988),

O dever do Estado com a educação será efetivado mediante a garantia de igualdade de condições para o acesso e permanência na educação básica obrigatória e gratuita dos 4 (quatro) aos 17 (dezessete) anos de idade, assegurada inclusive sua oferta gratuita para todos os que a ela não tiveram acesso na idade própria (BRASIL. 1988). 


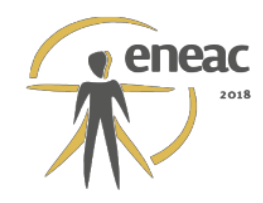

Contudo, poucas são as instituições de ensino que possuem uma estrutura adequada para prestar atendimento a esses usuários (PEIXOTO, 2005). No que se relaciona às pessoas com deficiência, Peixoto (2005) afirma que ações que permitam a inclusão educacional desses usuários muitas vezes não é priorizada pela falta de uma correta percepção da demanda existente e também pela alegação do alto custo das adaptações necessárias. Assim, é gerada uma espécie de círculo vicioso: não se facilita o acesso porque o número de alunos é baixo; o número de alunos continua baixo porque o acesso é difícil. De acordo com Silveira (2001) essa situação se reverteria caso houvesse condição favorável à sua inclusão no meio acadêmico através das eliminações das barreiras e da oferta de espaço funcional adequado para receber pessoas com deficiência.

Partindo desse contexto, este paper objetiva o estímulo à conscientização e ao interesse sobre inclusão e acessibilidade em comunidades escolares de ensino fundamental a partir do relato do projeto de extensão "Acessibilidade e inclusão básica: Uma abordagem multidisciplinar em escolas da rede pública municipal de João Pessoa-PB" (SARMENTO; PEREIRA; NOGUEIRA, 2017), desenvolvido no ano de 2017 na rede pública municipal de ensino desta cidade, com vistas à democratização do acesso aos espaços físicos e sociais, garantindo assim uma melhor na qualidade de vida e cidadania para todos. Cabe salientar que ações de cunho interdisciplinar de áreas distintas, Arquitetura e Urbanismo, o Design e a Terapia Ocupacional, mas complementares, possibilitaram uma visão mais abrangente da acessibilidade e da inclusão social. Levando-se em consideração que a Terapia Ocupacional tem como campo de estudo e intervenção o ser humano em sua relação funcional e ocupacional no desempenho de atividades cotidianas; o Design desenvolve projetos que utilizam a criatividade e a usabilidade para produzir itens inovadores, que cumpram fielmente com seu propósito de criação; e a Arquitetura e Urbanismo tem uma visão mais ampliada da relação de planejamento e projeto do ambiente construído e urbano. Assim, entrelaçar esses conhecimentos possibilitou uma relação global da acessibilidade, pertinentes ao sujeito (Terapia Ocupacional), ao objeto (Design) e ao ambiente (Arquitetura e Urbanismo). Além disto, possibilitou a equipe envolvida de ambos os cursos uma sensibilização para o trabalho interdisciplinar e para os aspectos fomentadores da acessibilidade.

\section{MÉTODO}

Para a elaboração do conteúdo exposto nas escolas foi realizada uma revisão conceitual, para o nivelamento da equipe e troca de saberes interdisciplinares, onde foram abordados os temas: acessibilidade, mobilidade, orientabilidade, desenho universal, legislação, pessoa com deficiência, educação, inclusão. Foram realizadas também pesquisa de vídeos que pudessem ilustrar tais conceitos.

De modo geral, a ação de abordar a acessibilidade e inclusão nas escolas foi pensada para ser, antes de quaisquer objetivos, interativa e de fácil entendimento para o público. Para tal, foi desenvolvida uma apresentação segundo a ordem: exposição de conteúdo, entremeada pela reprodução de vídeos, desenvolvimento de brincadeira sensorial, e encerrada com um feedback dos espectadores.

As palestras, que foram realizadas entre os meses de setembro e novembro de 2017, priorizaram as turmas de 4 ao 6ำ ano, tendo em vista a necessidade de abordar o assunto desde as primeiras séries do sistema municipal de ensino, para que a inclusão seja encarada como uma realidade. Foram visitadas quatro escolas, aqui denominadas escolas $A, B, C$ e D, sendo uma no bairro dos Estados (Escola $A-1$ turma $6^{\circ}$ ano), duas em Jaguaribe (Escola $B-1$ turma $4^{\circ}$ ano e $C-1$ turma $5^{\circ}$ ano) e uma em Mangabeira (Escola $D$ - 2 turmas do $5^{\circ}$ ano) (Tabela 1 ).

A partir das visitas as escolas do município, a experiência nos permitiu alcançar um público de cerca de 150 espectadores, incluindo estudantes e funcionários, pois muitos professores acompanharam a atividade em sala de aula. 


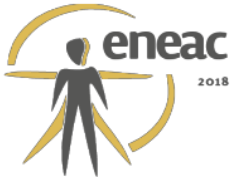

Tabela 1: Quantitativo de alunos nas escolas visitadas.

\begin{tabular}{|c|c|c|c|c|c|}
\hline & \multicolumn{4}{|c|}{ Escolas Visitadas } \\
\hline & & A & B & C & D \\
\hline \multirow{3}{*}{ 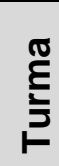 } & $4^{\circ}$ ano & & 27 & & \\
\hline & 5 ano & & & 24 & $24 / 25$ \\
\hline & $6^{\circ}$ ano & 32 & & & \\
\hline
\end{tabular}

Destaca-se que o apoio físico e de equipamentos para a atividade foi realizado pelo Laboratório de Acessibilidade LACESSE/DA/CT/UFPB.

\section{ESCOLAS MUNICIPAIS EM JOÃO PESSOA-PB}

Para as visitas o projeto previa iniciar pelas escolas que contabilizassem um maior número de pessoas com deficiência na cidade. Contudo, só obtivemos tais dados quando a atividade já estava em andamento, sendo possível ainda atingir o bairro de Mangabeira, que, assim como a maior parte dos bairros da Zona Sul, concentra escolas com mais de 100 crianças com deficiência (Figura 1).

Figura 1: Mapa da cidade de João Pessoa-PB, com quantitativo de alunos com deficiência matriculados por bairro.

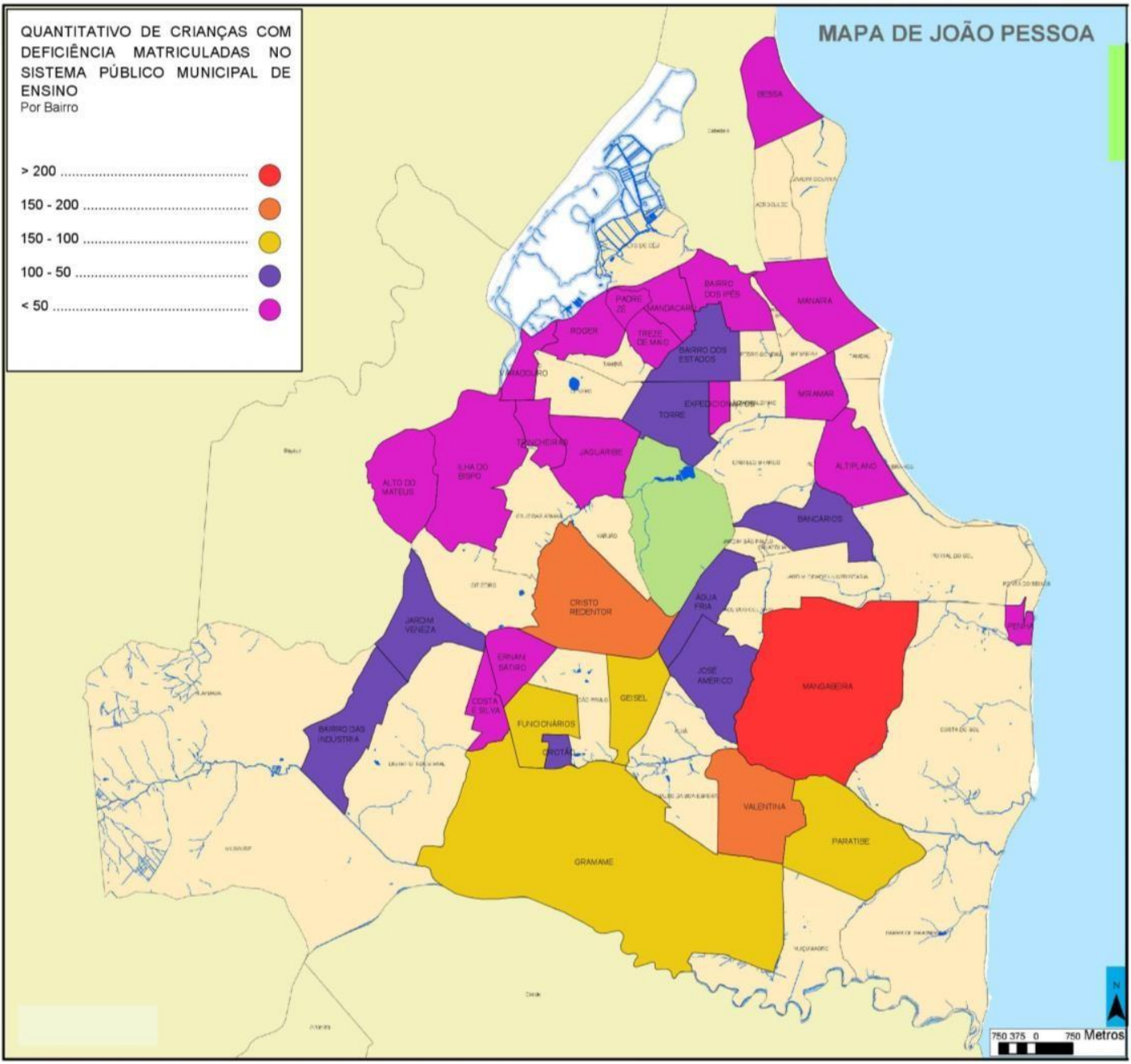

Fonte: Números mapeados a partir de dados fornecidos pela PMJP (2017). 


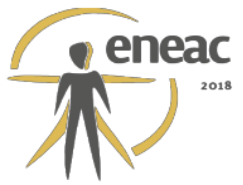

A cidade de João Pessoa - Paraíba soma um total de 95 escolas municipais, nas quais há um total de 2.544 crianças com deficiência matriculadas (PMJP, 2017) ${ }^{2}$.

\section{A PRÁTICA NAS ESCOLAS}

No ato de por em prática os planos teóricos, adaptações são quase que inerentes, não sendo diferente com a apresentação previamente planejada. Ao contrário do que se pensava, iniciar a dinâmica por uma brincadeira, quando se trata de crianças, pode deixar o ambiente conturbado e tirar o foco da apresentação devido ao estado de agito em que as crianças se encontram. A prática então mostrou que o oposto foi o mais eficaz, iniciando pelos conceitos de forma interativa, para já criar um laço entre o palestrante e o ouvinte, para só então chegar à brincadeira.

A exposição de conteúdo seguiu uma apresentação em formato PowerPoint (Figura 2), com uma linguagem simples e lúdica (Figura 1), onde, desde o início os estudantes eram questionados sobre o entendimento de determinado conceito, de foram a confrontar concordando ou corrigindo - os conceitos definidos pelos espectadores com aqueles apresentados, para melhor fixação do conteúdo, que explorou, de modo mais específico, o usuário e suas deficiências, a acessibilidade no ambiente construído e o design dos objetos e mobiliário presentes neste, de modo a integrar conhecimento dos profissionais envolvidos.

Figura 2: Tela de apresentação do material didático e Power Point.

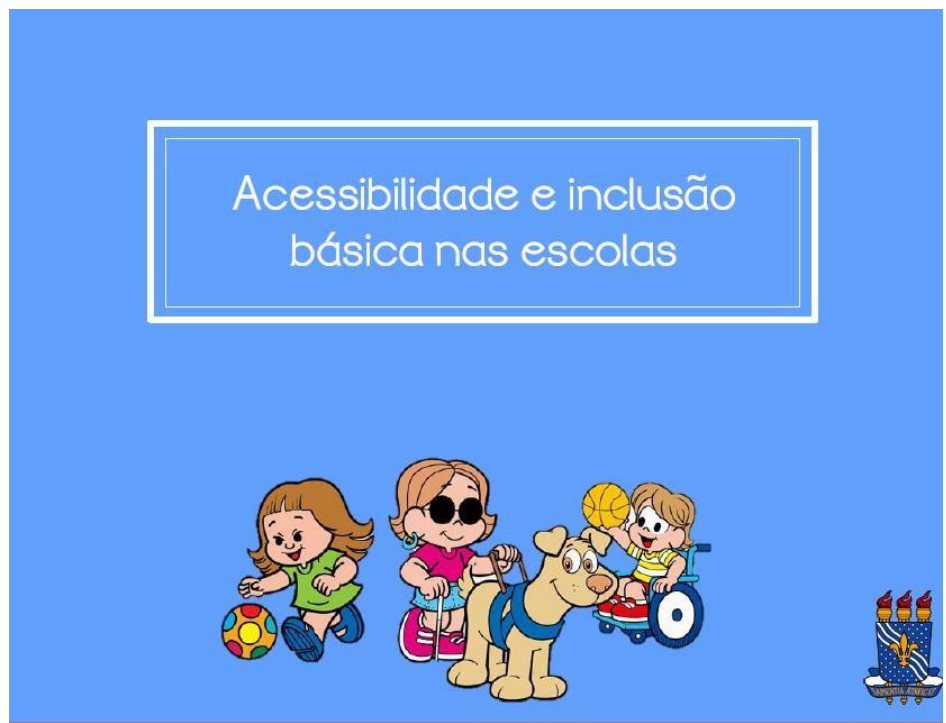

Fonte: Acervo do Projeto (2017).

Quando abordadas as deficiências (seus tipos e conceituação), a mobilidade reduzida e o tema da inclusão, a equipe buscou transmitir uma mensagem positiva de que todos são capazes de desenvolver qualquer atividade, apesar das suas limitações, e de que as diferenças jamais deverão ser motivo de exclusão (Figura 3). Foi também importante aproximar o assunto da realidade do público, fazendo associações com casos corriqueiros, a exemplo do "andar lento dos avós" ou "segurar sacolas ao fazer compras" com a mobilidade reduzida.

\footnotetext{
${ }^{2}$ Dados fornecidos pela Prefeitura Municipal de João Pessoa - PMJP, a partir da solicitação feita pela equipe do projeto via processo ํㅜㄴ 2017/117375 de 13 de novembro de 2017 .
} 


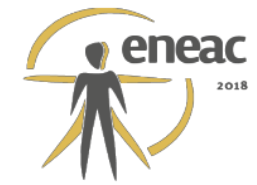

No momento em que se abordou a acessibilidade foram reproduzidos dois vídeos (Figura 4), sendo um deles sobre "Inclusão nas escolas", com um olhar voltado às barreiras físicas, e outro com "Dicas de convivência com a pessoa com deficiência", falando sobre as barreiras atitudinais. Nesse momento foi feita a relação das imagens com a realidade física das escolas.

Figuras 3 e 4: Apresentação no 4 ano na Escola B; e Apresentação de vídeos no $5^{\circ}$ ano na Escola D, respectivamente.

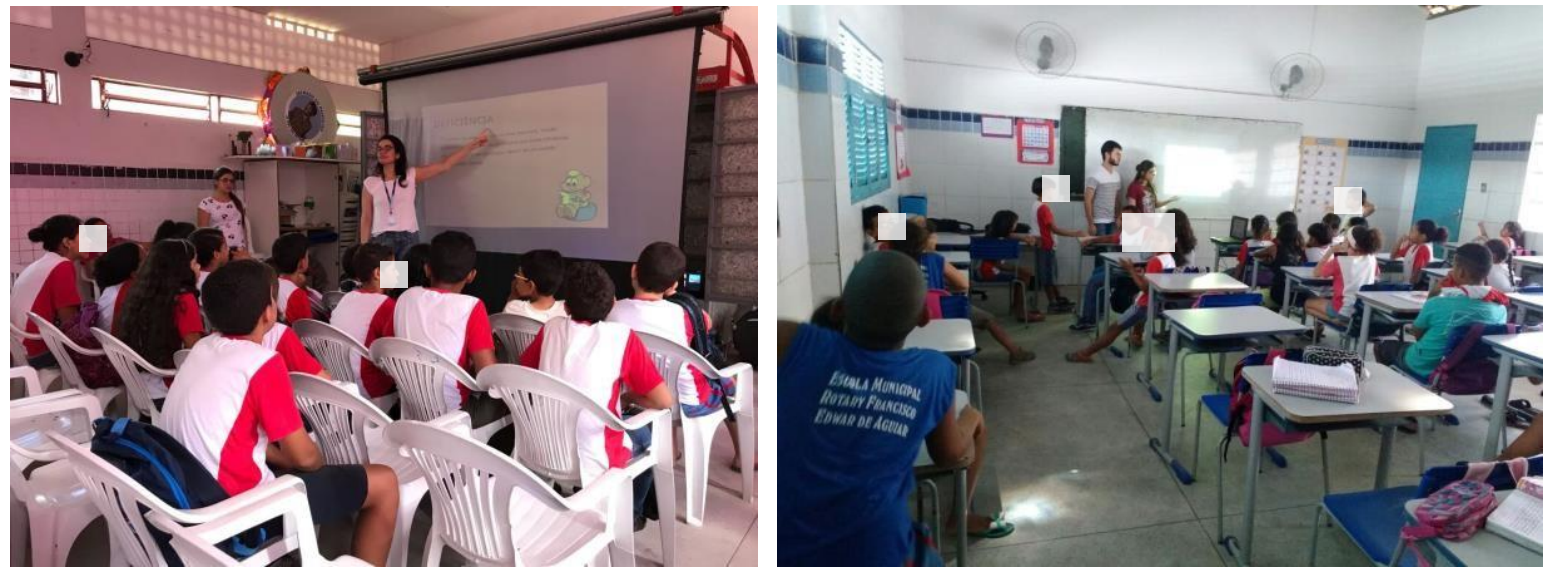

Fonte: Acervo do Projeto (2017).

Seguindo a exposição, foi abordado o Desenho Universal e seus sete princípios. Para melhor entendimento do público a respeito do que se trata o Desenho Universal foi importante observar as potencialidades do ambiente e objetos onde se ministrava a apresentação e utilizá-los como bons ou maus exemplos no exercício da inclusão. Atentar aos tipos de maçanetas das portas, às sinalizações espalhadas na escola, às carteiras dos estudantes, alturas de prateleiras, quadros, ventiladores e bebedores, e citá-los como casos em que o Desenho Universal foi atendido ou negligenciado.

Exposto esse conteúdo, ressaltou, como tentativa de mitigar essa mazela social no âmbito escolar, estimular o diálogo entre os estudantes e o exercício da boa convivência (Figura 5), $\mathrm{o}$ ato do bullying, praticado seja por fatores físicos ou comportamentais.

Figura 5: Apresentação no 5ำ ano na Escola C.

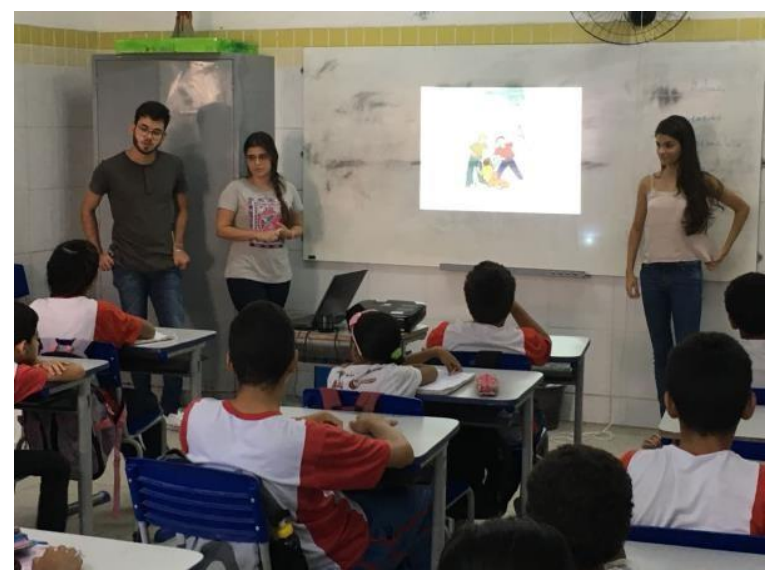

Fonte: Acervo do Projeto (2017). 


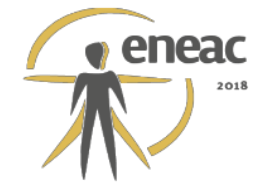

A etapa de exposição de conteúdo é então finalizada com a exposição dos facilitadores das pessoas com deficiência na UFPB, mas tendendo também a estimular a vontade de estudar no público e o ingresso numa universidade pública.

Após a fase da apresentação conceitual e vídeos, os alunos eram convidados a participar de brincadeira "dança das cadeiras", onde simulavam ter alguma deficiência, onde parte da sala era separada em quatro grupos, por cores, sendo cada uma representante de uma deficiência ou mobilidade reduzida. São elas: Azul - Deficiência física (cegueira); Rosa Mobilidade reduzida (tipóia); Amarelo - Deficiência física (braços amarrados); Laranja Deficiência física (pernas amarradas). Vale salientar que o tempo ocupado com a fase de exposição de conteúdo é que determinará quantos serão os participantes envolvidos na brincadeira, haja vista a duração da atividade geral que não ultrapassava $1 \mathrm{~h}$.

O layout das cadeiras era determinado pelo espaço que se tinha para realização da atividade, podendo ser em círculo, como acontece tradicionalmente, ou em linha reta, posicionando as cadeiras uma ao lado da outra (Figuras 6 e 7). Não diferente da tradicional, a brincadeira tinha início ao play da música (que deve estar em tom audível, pois provavelmente haverá agito por parte da turma), que é quando os participantes andavam em volta das cadeiras até que a música fosse pausada. Quem não estivesse sentado quando a música parasse deveria deixar o jogo, entregando sua faixa, e a partida era reiniciada com menos uma cadeira. A ação era repetida até restar somente um participante sentado.

Figura 6 e 7: Brincadeira com o 4ํ ano da Escola B; e Brincadeira com o 5 ano D.

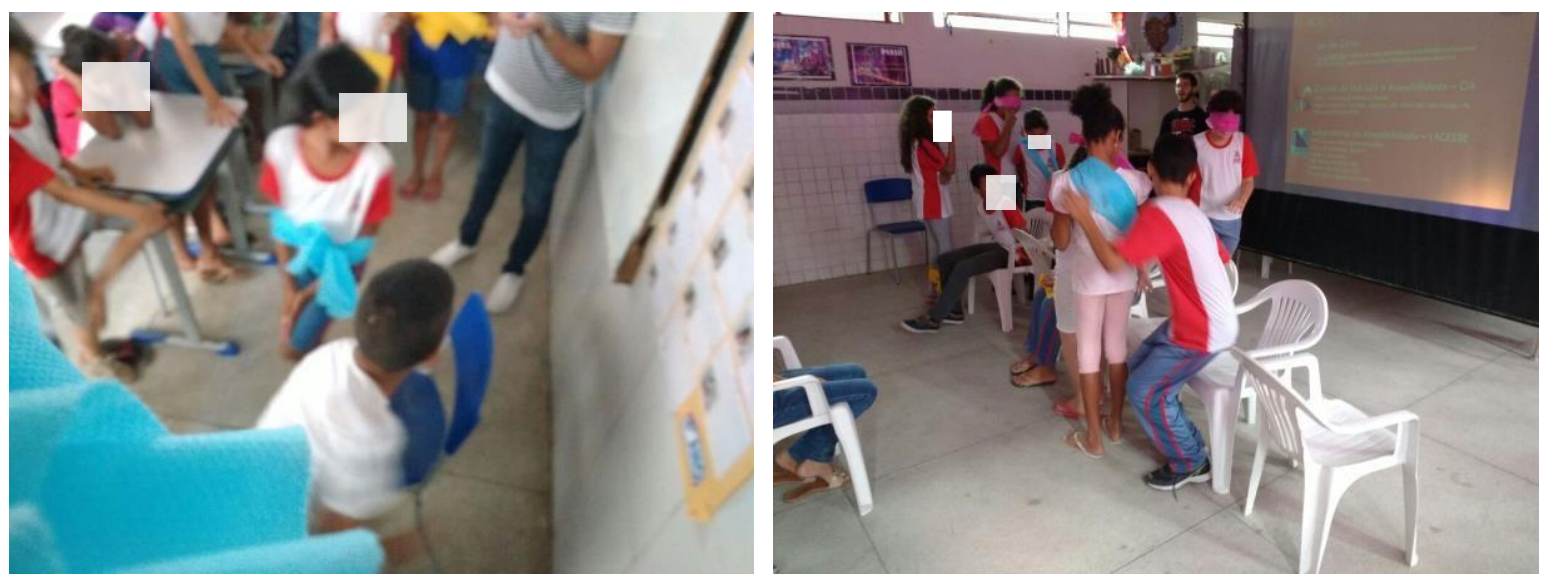

Fonte: Acervo do Projeto (2017).

A brincadeira era então finalizada com o retorno dos estudantes sobre o que foi apreendido com relação às deficiências e às dificuldades que elas implicam. Esse questionamento era feito principalmente aos participantes da brincadeira, que tiveram a oportunidade de simular algum dos obstáculos enfrentados pelas pessoas com deficiência. E importante reforçar a mensagem do ato inclusivo e agradecer o envolvimento da turma no decorrer da atividade.

Outro fator de destaque na etapa "prática" do projeto é a forma como a própria escola conduz e se envolve com o serviço prestado, isso da diretoria ao professor. Quando se tem o apoio da unidade educacional, a prática se torna mais facilmente guiada, a exemplo da Escola D, no Bairro de Mangabeira, onde as palestras foram realizadas em duas turmas de $5^{\circ}$ ano e, em ambas, os professores interagiram, estimularam as crianças a tomar posturas coerentes com que estava sendo repassado e ainda incentivaram nas crianças a atitude crítica de denunciar aos responsáveis àquilo que elas julguem errado no ambiente escolar físico e atitudinal. 


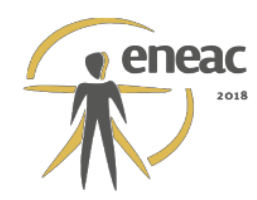

Em duas das escolas visitadas, Escola A e Escola B, foi um tanto quanto difícil lidar com os alunos, inquietos a todo instante (principalmente por termos iniciado, na Escola $A$, com os vídeos), mas só em percebermos que conseguimos repassar o conteúdo, mesmo que para os que permaneceram atentos, o resultado já nos foi satisfatório. Nas demais escolas, a apresentação ocorreu de forma exemplar, deixando na equipe o desejo de retornar à unidade e repassar os conhecimentos para outras turmas.

\section{CONSIDERAÇÕES FINAIS}

A carência do debate sobre acessibilidade nas escolas e a necessidade de repassar o conhecimento acerca da temática, para que este seja enraizada no cotidiano escolar desde as séries que compõem sua base, contribui para a formação de uma sociedade mais justa e igualitária.

O repasse dos conhecimentos sobre acessibilidade e inclusão, promovido pelo projeto de extensão, estabelece a aproximação entre a Universidade e a comunidade para a qual os serviços devem ser voltados, e desta com uma realidade que parece alheia ao que tange as obrigações sociais no processo inclusivo das pessoas com deficiência, mas que não é. Instigar a sociedade a aceitar e respeitar as diferenças é um dos passos mais importantes no exercício de mitigação e superação das barreiras enfrentadas por pessoas com deficiência.

Diante do exposto, este artigo teve um caráter social e educativo, através da apresentação de uma problemática atual e relevante, a discussão e troca de saberes sobre acessibilidade e inclusão, principalmente depois do advento da Lei 13.146 (BRASIL, 2015) ou Lei Brasileira da Inclusão da Pessoa com Deficiência, destinada a assegurar e a promover, em condições de igualdade, o exercício dos direitos e das liberdades fundamentais por pessoa com deficiência, visando à sua inclusão social e cidadania. Este projeto gerou ainda importante desenvolvimento pessoal e profissional dos envolvidos, além de permitir que os atores das instituições educacionais públicas (alunos, professores, funcionários) fossem conscientizados para uma proposta de espaço acessível, livre de barreiras, e de perspectivas da inclusão social da pessoa com deficiência no ambiente escolar.

\section{REFERÊNCIAS BIBLIOGRÁFICAS}

ASSOCIAÇÃO BRASILEIRA DE NORMAS TÉCNICAS. NBR 9050: Acessibilidade a edificações, mobiliário, espaços e equipamentos urbanos. Rio de Janeiro: ABNT, 2015.

BINS ELY, Vera Helena Moro. Acessibilidade Espacial: condição necessária para o projeto de ambientes inclusivos. In: MORAES, Anamaria de (Org.). Ergodesign do ambiente construído e habitado: ambiente urbano, ambiente público, ambiente laboral. 2. ed. Rio de Janeiro: iUsEr, 2004.

BRASIL. Constituição da República Federativa do Brasil. Brasília, DF: Senado Federal: Centro Gráfico, 1988. 292 p.

BRASIL. Decreto lei no 5.296, de 02 de dezembro de 2004. Regulamenta as Leis no 10.048, de 8 de novembro de 2000 e 10.098, de 19 de dezembro de 2000. Estabelece normas gerias e critérios básicos para a promoção da acessibilidade das pessoas com deficiência ou com mobilidade reduzida. Disponível em: http://www.acessobrasil.org.br/index.php?itemid=43. Acesso em: 02 mai. 2010.

BRASIL. LEI № 10.048, DE 8 DE NOVEMBRO DE 2000. Dá prioridade de atendimento às pessoas que especifica, e dá outras providências. 2000a.

BRASIL. LEI № 10.098, DE 19 DE DEZEMBRO DE 2000. Estabelece normas gerais e critérios básicos para a promoção da acessibilidade das pessoas portadoras de deficiência ou com mobilidade 


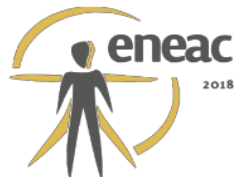

reduzida. 2000b. 


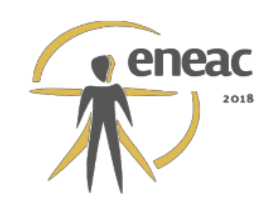

BRASIL. LEI № 13.146, DE 6 DE JULHO DE 2015. Institui a Lei Brasileira de Inclusão da Pessoa com Deficiência (Estatuto da Pessoa com Deficiência). 2015.

DUARTE, Cristiane Rose de Siqueira ; COHEN, R.. Acessibilidade aos Espaços de Ensino e Pesquisa: Desenho Universal na UFRJ Possível ou Utópico? In: In: NUTAU 2004: DEMANDAS SOCIAIS, INOVAÇÕES TECNOLÓGICAS E A CIDADE, 2004, São Paulo. Anais... São Paulo, 2004.

PEIXOTO, Dalila Maria Grandi Monteiro. Acessibilidade Física ao Meio Edificado do Campus Universitário da UFES: discussão, diretrizes de projeto e propostas. Dissertação (Programa de PósGraduação em Engenharia Civil) UFES, Vitória: 2005.

SARMENTO, Bruna Ramalho; PEREIRA, Leandro Lopes; NOGUEIRA, Dhyego de Lima. Acessibilidade e inclusão básica: Uma abordagem multidisciplinar em escolas da rede pública municipal de João Pessoa-PB. Projeto de extensão (Documento interno). João Pessoa-PB: UFPB, 2017.

SILVEIRA, Júlia Gonçalves da. Biblioteca inclusiva?: repensando barreiras de acesso aos deficientes físicos e visuais no Sistema de Bibliotecas da UFMG e revendo trajetória institucional na busca de soluções. In: SEMINÁRIO NACIONAL DE BIBLIOTECAS UNIVERSITÁRIAS, 11., 2000, Florianópolis.

Anais... Florianópolis: Universidade Federal de Santa Catarina, 2000. 